\title{
The Synthesize and Property Evaluation of High Temperature Resistant Phenolic Resin-Type Profile Control Agent
}

\author{
Qingwang Liu, Hongwei Mu, Jigang Wang, Zhenzhong Fan \\ EOR Key Laboratory of the Ministry of Education, Northeast Petroleum University, Daqing City, China \\ Email: LIUQINGWANG@163.com, 7591541@qq.com, wangjigang9999@163.com, fanzhenzhong@163.com
}

Received 30 June 2014; revised 10 July 2014; accepted 20 July 2014

Copyright (C) 2014 by authors and Scientific Research Publishing Inc.

This work is licensed under the Creative Commons Attribution International License (CC BY). http://creativecommons.org/licenses/by/4.0/

(c) (i) Open Access

\begin{abstract}
Most of the mining method of domestic oilfield is waterflood development, thus the water content in the mid and late water flooding would rise faster, and the oil recovery rate would decline relatively more rapid. So it is very important to research profile control agent for stabilizing oil production resin-type profile control agent, and focus on researching the themal stability, shear resistance, gelation time and gelation strength and other properties of this profile control agent [1]. Finally, the best ratio for synthesizing the high temperature resistant phenolic resin-type profile control agent was obtained.
\end{abstract}

Keywords

Waterflood Development, Phenolic Resin, Profile Control Agent

\section{Introduction}

Currently, the profile control technology in oilfield appears some new trends. The major ones are mainly weak gel flooding technology, heavy oil thermal recovery wells high temperature profile control technology, deep/ultra-deep well profile control technology, the profile control techniques of injection polymer reservoirs etc. After years of development, two major categories of mechanical and chemical profile control technology have been formed. Correspondingly, the successful development of the eight categories of hundreds of species profile controls chemical agents [2]. Developed multiple machinery profile control column for the vertical well, deviated well and mechanical productive wells, support and improve the numerical simulation technology, profile control target screening technology and other seven sets of technology. In order to improve mining efficiency, waterflood development oilfield has made important contributions to carrying out the mechanism studies, conducted 
test study of microscopic and the physical model of magnetic resonance imaging, making deeper understanding of the profile control mechanism.

\section{Experimental and Results}

\subsection{The Synthesize of High Temperature Resistant Phenolic Resin-Type Profile Control Agent}

\subsubsection{The Synthetize of Water-Soluble Phenolic Resin}

Use two-step method to synthesis water-soluble phenolic resin, the optimum reaction condition is that the molar ratio of phenol:formaldehyde:sodium hydroxide is 1:3:0.3. Product obtained is brown-red, in the synthesis process, reaction time and the temperature of the water bath should be strictly controlled [3]. Water bath should be increase steadily, the last reaction time is best 30 min since polycondensation reaction.

\subsubsection{The Synthesize of High Temperature Resistant Phenolic Resin-Type Profile Control Agent}

Take the polyacrylamide solution had formulated already which concentration is $0.3 \%$, and the water-soluble phenolic resin mixed together according to a certain proportion of electronic constant speed mixer stirred uniformly, poured into a large glass test tube. Put labels and placed into constant temperature water bath of 80 degree Celsius, then observe gelation time after standing around $14 \mathrm{~h}$.

\subsection{The Property Evaluation of High Temperature Resistant Phenolic Resin-Type Profile Control Agent}

\subsubsection{The Thermal Stability of High Temperature Resistant Phenolic Resin-Type Profile Control Agent}

The different oil reservoir buried at different depths and the corresponding formation temperature will be different, which requires suitable for the profile agent of different temperature. This experiment was configured concentration of $0.2 \%$ and $0.3 \%$ aqueous solution of polyacrylamide, poured the water-soluble phenolic resin configured already into two different concentrations of polyacrylamide solution and stir evenly, then put it in a water bath of $80^{\circ} \mathrm{C}$ curing. Come up with it periodically and observe the color and gelation status, the experimental results are shown in Table 1.

Table 1. The temperature resistance experiment of high temperature resistant phenolic resin-type profile control agent.

\begin{tabular}{ccc}
\hline \multirow{2}{*}{ Observation time } & \multicolumn{2}{c}{ Gelation strength mPa·s } \\
\cline { 2 - 3 } 3 d & Polymer concentration $0.2 \%$ & Polymer concentration $0.3 \%$ \\
4 d & 9506 & 13,175 \\
5 d & 9389 & 13,001 \\
6 d & 9174 & 12,817 \\
7 d & 9025 & 12,680 \\
8d & 8869 & 12,530 \\
9 d & 8700 & 12,342 \\
10 d & 8573 & 12,209 \\
11 d & 8432 & 12,077 \\
12 d & 8301 & 11,935 \\
13 d & 8182 & 11,801 \\
14 d & 8060 & 11,675 \\
15 d & 7927 & 11,538 \\
16 d & 7799 & 11,414 \\
17 d & 7708 & 11,347 \\
30 d & 7698 & 11,304 \\
\hline
\end{tabular}


The experimental results in Table 1 show that the polymer concentration of $0.2 \%$ and $0.3 \%$, the initial viscosity after gelation were $9506 \mathrm{mPa} \cdot \mathrm{s}$ and $13175 \mathrm{mPa} \cdot \mathrm{s}$, the intensity decline after standing at ambient of $80^{\circ} \mathrm{C} 16 \mathrm{~d}$, and the basic initial viscosity of about $80 \%$, but when placing reached $30 \mathrm{~d}$, little change in its strength and roughly equal with the $16 \mathrm{~d}$ ago. It can be seen that the profile control agent has good stability at ambient of $80^{\circ} \mathrm{C}$, improve the profile control and displacement measures role of the effective time.

\subsubsection{The Gelation Time of High Temperature Resistant Phenolic Resin-Type Profile Control Agent} The gelation time of profile control agent is an important factor in directly affects the can proceed smoothly of construction site, and the application of more methods to determine the gelation time is by determining the change in the viscosity of profile control agent obtained [4]. Use the water of Jilin water wells formulated aqueous polyacrylamide solution in this experiment, when the concentration is $0.2 \%$, the gelation time as shown in Table 2.

Table 2 shows the conditions at $80^{\circ} \mathrm{C}$, the gel viscosity changed little in the beginning of nine hours conservation, when the rapid increase in the gel viscosity curing nine hours later and the gel viscosity increases slowed when the curing time of 18 hours. It can be think that, the gelation time of high-temperature profile control agent is 18 hours under the environmental temperature of $80^{\circ} \mathrm{C}$.

\subsubsection{The Gelation Strength of High Temperature Resistant Phenolic Resin-Type Profile Control Agent}

The gelation strength of profile control agent is a important factor to profile control the directly influences effect. The profile control agent is mixed with the water-soluble phenolic resin from the polyacrylamide solution which concentration is $0.2 \%$, stirring with electronic uniform speed stirrer sufficiently, then put it into water bath of $80^{\circ} \mathrm{C}$ and measured the intensity regular intervals. Its viscosity is used here to represent the intensity and the measurement results in the following Table 3.

Table 3 shows the gel liquid viscosity will not change when it reached $6045 \mathrm{mPa} \cdot \mathrm{s}$ and it can be regarded as a gum, the gel viscosity of $6045 \mathrm{mPa} \cdot \mathrm{s}$ can be considered as the gel strength. Measured gel viscosity with rotary viscometer often appear climbing pole, gel breaking and other phenomenons, lead to the determination of viscosity value exception after glue into Figure 1.

\subsubsection{The Shear Resistance of High Temperature Resistant Phenolic Resin-Type Profile Control Agent}

The formulation of profile control agent in this experimental is selected from $0.2 \%$ polyacrylamide and $45 \%$ water-soluble phenolic resin, measured according to the method of the gelation strength of profile control agent and measured the gelation strength of had been cut and not cut profile control agent, thus evaluate the shear resistance.

From the data in Table 4 to calculate the viscosity decreased rate is $15.2 \%$, shows the shear resistance of high temperature resistant phenolic resin-type profile control agent is better of $130^{\circ} \mathrm{C}$, because the gel is formed network structure by polymer in solution to lock moisture, it formed with the loss of mobility. However, frequent shear cause the degradation of polymer and thus such a network structure, resulted in a decline in the gel strength of characterization dynamic viscosity.

\section{Conclusions}

1) General profile control agent will change its performance at high temperatures and it can not block the hypertonic aquifer, therefore it can not play the role of stabilizing oil and controlling water. The temperature resistance

Table 2. The gelation time of high temperature resistant phenolic resin-type profile control agent.

\begin{tabular}{ccccccccc}
\hline Time h & 3 & 6 & 9 & 12 & 15 & 18 & 21 & 24 \\
Viscosity $\mathrm{mPa} \cdot \mathrm{s}$ & 1024 & 1369 & 1654 & 2979 & 4105 & 5318 & 5702 & 6045 \\
\hline
\end{tabular}

Table 3. The gelation strength of high temperature resistant phenolic resin-type profile control agent.

\begin{tabular}{ccccccccc}
\hline Time h & 3 & 6 & 9 & 12 & 15 & 18 & 21 & 24 \\
Viscosity $\mathrm{mPa} \cdot \mathrm{s}$ & 1024 & 1369 & 1654 & 2979 & 4105 & 5318 & 5702 & 6045 \\
\hline
\end{tabular}




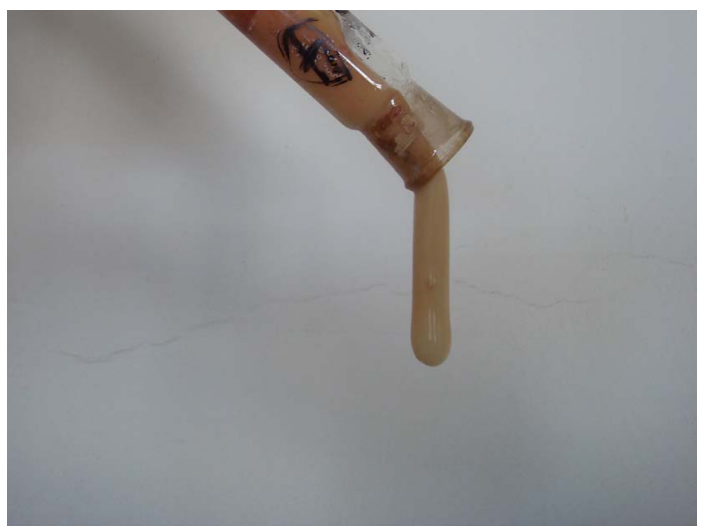

Figure 1. The image after gelation.

Table 4. The shear resistance of high temperature resistant phenolic resin-type profile control agent.

\begin{tabular}{cc}
\hline Not cut profile control agent & Had been cut profile control agent \\
\hline $6045 \mathrm{mPa} \cdot \mathrm{s}$ & $5138 \mathrm{mPa} \cdot \mathrm{s}$ \\
\hline
\end{tabular}

of phenolic resin is very good, with phenolic resin and an aqueous solution of polyacrylamide configured the profile control agent at $80^{\circ} \mathrm{C}$ can play the efficacy of stabilizing oil and control water.

2) The performance of profile control agent has a great impact on the content of water-soluble phenolic resin, the more content of water-soluble phenolic resin, the shorter gelation time of profile control agent and the gelation strength is stronger.

3) The outcome of the experiment is when the content of water-soluble phenolic resin is $0.5 \%$ and the aqueous solution of polyacrylamide is $0.3 \%$, the gelling results will be ideal, compared to other formulations is relatively inexpensive.

\section{Acknowledgements}

The project is funded by the National Natural Science Foundation of the Study of Mechanism on Oil Soluble Resin-dual Cross-linked-gelatinous Water Shutoff Agent. Fund No.: 51374071.

\section{References}

[1] Xiao, C.M. and Wang, Z.L. (2003) The Summary of Oilfield Chemistry Water Shutoff Profile. Advances in Fine Petrochemicals, 3, 1-3.

[2] Qi, Y. (2005) The Property Evaluation of High Temperature Resistant Phenolic Resin-Type Profile Control Agent. Journal of Chemical and Biological Engineering, 1, 6-9.

[3] Zhao, F.L. (1994) The Technology of Oil and Gas Recovery Factor of the Profile Control Agent and Oil Displacement Agent. Oil Journal, 1, 1-5.

[4] Zhu, Y.M. (2006) The Progress of Foreign Phenolic Resins and Plastics Industry. Thermosetting Resins, 3, $29-34$. 
Scientific Research Publishing (SCIRP) is one of the largest Open Access journal publishers. It is currently publishing more than 200 open access, online, peer-reviewed journals covering a wide range of academic disciplines. SCIRP serves the worldwide academic communities and contributes to the progress and application of science with its publication.

Other selected journals from SCIRP are listed as below. Submit your manuscript to us via either submit@scirp.org or Online Submission Portal.
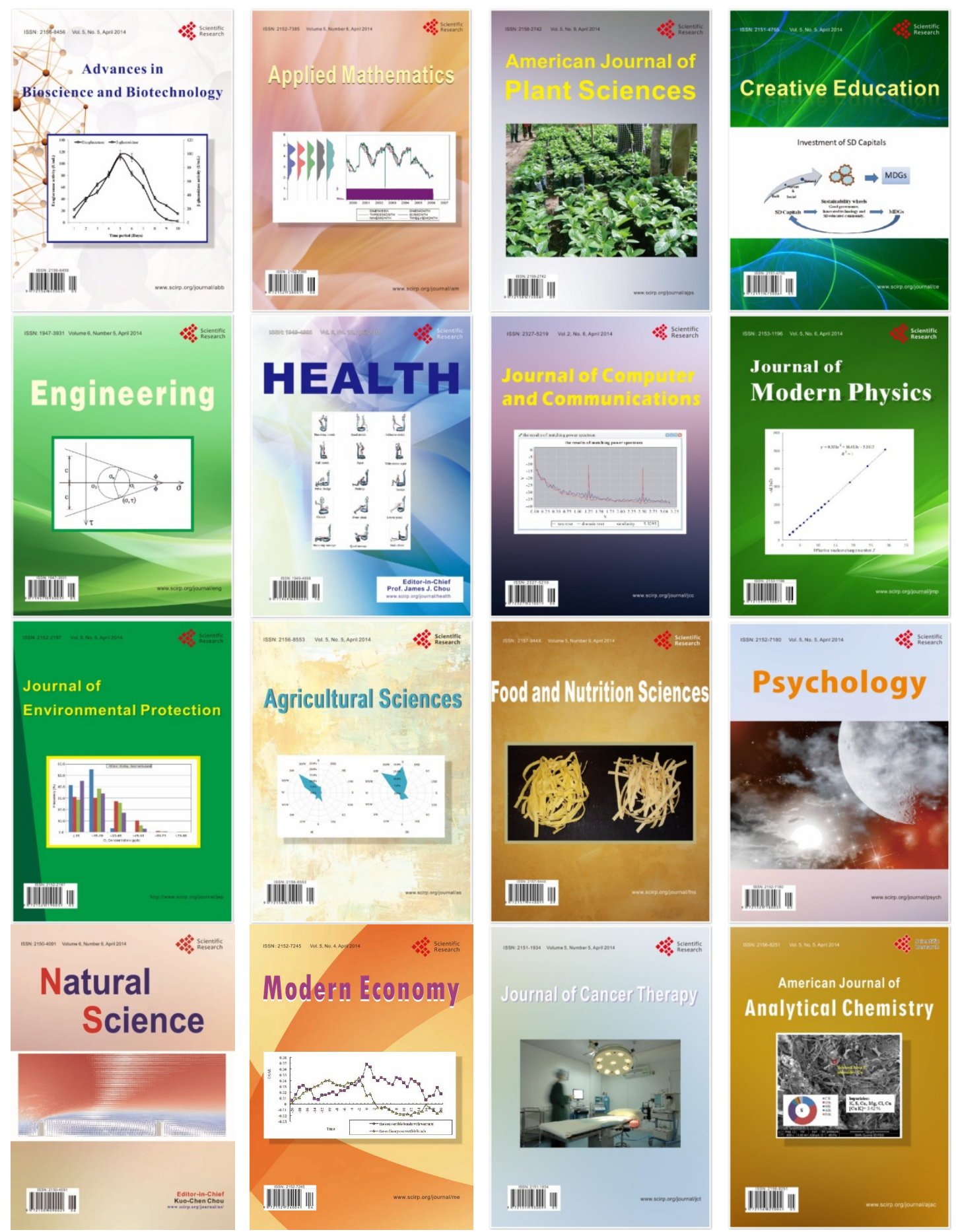